\title{
The Selective TP Receptor Antagonist, S18886 (Terutroban), Attenuates Renal Damage in the Double Transgenic Rat Model of Hypertension
}

\author{
Katarína Šebekováa Anika Ramuscak ${ }^{\mathrm{b}}$ Peter Boor ${ }^{\mathrm{a}} \quad$ August Heidland $^{\mathrm{c}}$ \\ Kerstin Amann ${ }^{b}$ \\ aSlovak Medical University, Bratislava, Slovakia; ${ }^{b}$ University of Erlangen-Nürnberg, Erlangen, and \\ 'University of Würzburg, Würzburg, Germany
}

\section{Key Words}

Renin-angiotensin system • Hypertension - Thromboxane •

Glomerulosclerosis · Tubulointerstitial damage •

Proteinuria

\begin{abstract}
Background/Aims: Thromboxane receptors play a decisive role in the renovascular actions of angiotensin II. We studied the efficacy of the selective thromboxane receptor antagonist, S18886, in the retardation of renal damage in the double transgenic rats (dTGR), harboring human renin and angiotensinogen genes. Methods: dTGR were gavaged daily with either $\mathrm{S} 18886(30 \mathrm{mg} / \mathrm{kg} / \mathrm{day}, \mathrm{n}=12)$, or placebo (dTGRPlac, tap water, $n=14$ ) for 3 weeks. Matched Sprague-Dawley rats $(n=10)$ served as controls. Results: The dTGR-Plac had higher systolic blood pressure (1.7-fold) than controls, and developed profound renal damage with significantly higher proteinuria (6.9-fold), polyuria (2.3-fold), index of glomerulosclerosis $(+58 \%)$, and tubulointerstitial $(+47 \%)$ and vascular damage scores (+19\%). Creatinine concentration and the mesangiolysis index remained unchanged. In dTGR, S18886 slightly lowered the blood pressure (162 \pm 15 vs. 149 $\pm 13 \mathrm{~mm} \mathrm{Hg}$, not significant) and improved proteinuria (558 \pm 218 vs. $136 \pm 71 \mathrm{mg} / \mu \mathrm{mol}$ creatinine, $\mathrm{p}<0.01$ ), polyuria and renal morphology (glomerulosclerosis index: $0.79 \pm$ 0.05 vs. $0.66 \pm 0.13, p<0.01$; tubulointerstitial damage index: $1.82 \pm 0.22$ vs. $1.49 \pm 0.27, p<0.05$; mesangiolysis index: $1.31 \pm 0.18$ vs. $0.36 \pm 0.09, p<0.01)$. Vascular damage
\end{abstract}

score and plasma creatinine were not influenced. S18886 did not alter measured markers of oxidative stress. Conclusion: The data present the first evidence that thromboxane receptor inhibition ameliorates angiotensin II-induced nephropathy.

\footnotetext{
Copyright $\odot 2007$ S. Karger AG, Basel
}

\section{Introduction}

Angiotensin II (Ang-II) activates vasopressor mechanisms and, in subpressor doses, induces oxidative stress in the vessel wall, heart and kidney $[1,2]$, potentiating its vasoconstrictory effects. It stimulates the synthesis of isoprostanes, which may contribute to the pressor response via induction of vasoconstriction and renal sodium retention $[1,3]$. Hence, thromboxane $\mathrm{A}_{2}\left(\mathrm{TXA}_{2}\right)$ binds to thromboxane receptors (TPr) in renal vascular tissue and thereby aggravates vascular damage $[3,4]$. TXA 2 induces contraction of mesangial cells, the glomeruli and the afferent/efferent arterioles [5]. In the central nervous system the dipsogenic action of Ang-II seems to be mediated via the TPr [6].

S18886, a polysubstituted tetrahydronaphthalene derivative, is a new highly selective, long-acting TPr antagonist [7] with potent antiplatelet, antivasoconstrictory and antiproliferative effects. It antagonizes the binding of $\mathrm{TXA}_{2}$, and the other arachidonic acid metabolites (i.e. prostaglandins, HETE acids, isoprostanes) to TPr with

\section{KARGER}

www.karger.com 
different rank order of potency [8]. These actions render the substance beneficial in the prevention of hypertension or atherosclerosis-associated organ damage $[7,9]$. S18886 inhibited the development of atherosclerosis in rabbit models [10, 11], and in apolipoprotein E-deficient $\left(\mathrm{apoE}^{-/-}\right)$mice $[12,13]$. It exerted renoprotective and antioxidant actions in diabetic apoE $\mathrm{E}^{-/-}$mice [14] and in obese Zucker rats [15].

Double transgenic rats (dTGR, harboring human renin and angiotensinogen genes) develop accelerated hypertension leading to marked damage of the kidney, and heart [16]. Ang-II-induced inflammatory response contributes to fatal organ damage [17]. Since TPr play a decisive role in the Ang-II-dependent alterations of renal hemodynamics and oxidative stress, we hypothesized that TPr antagonism with S18886 may retard the renal injury in the dTGR model.

\section{Animals and Methods}

The investigation was conducted according to the guidelines for studies using laboratory animals, after approval of the protocol by the Institutional Ethics Committee for Experimental Animals (Bratislava, Slovakia).

\section{Rats}

Four-week-old male dTGR (RCC Ltd, Füllinsdorf, Switzerland) received a daily gavage of either $\mathrm{S} 18886(30 \mathrm{mg} / \mathrm{kg}, \mathrm{n}=12)$, or placebo (dTGR-Plac, tap water, $\mathrm{n}=14$ ) for 3 weeks. Control Sprague-Dawley rats (SD, Charles River, Sulzfeld, Germany, $\mathrm{n}=$ 10) received placebo. Animals had free access to drinking water and a standard rat chow. None of the animals died during the study.

\section{Experimental Protocol}

Before sacrifice, body weight and systolic blood pressure (SBP, tail plethysmography) were recorded, and 24-hour urine collected. At sacrifice, blood was sampled from the abdominal aorta under anesthesia. Kidneys and heart were removed after retrograde perfusion fixation with glutaraldehyde via the abdominal aorta as previously described [18]. Routine blood and urine chemistry was measured by an autoanalyzer (Vitros 250, J\&J, Rochester, N.Y., USA), plasma malondialdehyde (MDA) by HPLC with fluorimetric detection [19], erythrocyte glutathione peroxidase (GPX) and superoxide dismutase (SOD) activity by commercial kits (Randox, Crumlin, UK). Urine osmolarity was determined. Creatinine clearance was calculated.

\section{Tissue Preparation}

Semithin and paraffin-embedded kidney sections stained with methylene blue/basic fuchsin and hematoxylin and eosin (HE) or periodic acid-Schiff (PAS), respectively, were prepared as described previously [15]. Histomorphological evaluations were performed in a blinded manner.
Semiquantitative Indices of Mesangiolysis (MGI),

Glomerulosclerosis (GSI), Tubulointerstitial (TSI) and

Vascular Damage (VSI)

Damage of mesangial or endothelial cells and of the mesangial matrix, i.e. the mesangiolysis score ( $0-4$; MGI); mesangial matrix expansion, i.e. the glomerulosclerosis score (0-4; GSI); tubulointerstitial damage $(0-4$; TSI), i.e. tubular dilatation, tubular atrophy, interstitial inflammation and fibrosis, and vascular damage (0-4; VSI), i.e. wall-thickening and fibrinoid necrosis, were assessed on PAS sections as described $[15,20]$.

\section{Glomerular Geometry}

Glomerular geometry and area density of glomerular tuft were analyzed at a magnification of $400 \times$ on $\mathrm{HE}$ sections [18, 20, 21]. The total number of glomeruli was derived from the total volume of the renal cortex and the number of glomeruli per cortex volume, and the mean glomerular tuft volume was calculated [21].

\section{Glomerular Cells and Capillaries}

Semithin sections were qualitatively inspected for glomerular cellular changes, i.e. podocyte enlargement and degeneration, and mesangial or endothelial cell hyperplasia. Glomerular capillarization and cellularity were counted on 5 semithin sections (at least 30 glomeruli per animal) as described previously [18]. The number of cells (mesangial, endothelial, parietal cells, and podocytes) per glomerulus was determined $[18,15]$.

\section{Statistics}

The data were tested for normality and equality of variance, and appropriate tests were applied to compare the data, i.e. oneway analysis of variance (ANOVA) with post-hoc Scheffés test, or Kruskal-Wallis with Mann-Whitney U-tests. Results are given as mean $\pm \mathrm{SD}$, or as median, mean $\pm \mathrm{SD}$ (not normally distributed data). $\mathrm{p}<0.05$ was considered significant.

\section{Results}

\section{Comparison between dTGR-Plac and SD (table 1)}

dTGR-Plac developed hypertension (+63 $\mathrm{mm} \mathrm{Hg}$ ), heart hypertrophy, and renal damage. Kidney to body weight ratio, plasma creatinine concentration and creatinine clearance remained comparable. dTGR developed proteinuria (6.9-fold), polyuria (2.2-fold), had lower urine osmolarity (-60\%), and mild glomerulosclerosis (fig. 1, $2 \mathrm{a}, \mathrm{b})$, more substantial tubulointerstitial and vascular damage (fig. 1, 2g). Glomerular cell number was significantly higher in the dTGR-Plac, indicating mild glomerular hypercellularity, particularly of mesangial and endothelial cells (fig. 2j, k; table 1). The significantly higher length density (total capillary length per glomerular volume), and lower mean capillary cross-sectional area indicated lengthening and remodeling of glomerular capillaries with narrowing of capillary lumina in dTGR-Plac. No changes in mesangiolysis or mean glomerular volume were observed (fig. 1, 2d, e; table 1). 
Table 1. Animal data and renal morphology

\begin{tabular}{|c|c|c|c|c|c|}
\hline & \multirow{2}{*}{$\begin{array}{l}\text { SD } \\
(n=10)\end{array}$} & \multirow{2}{*}{$\begin{array}{l}\text { dTGR-Plac } \\
(\mathrm{n}=14)\end{array}$} & \multirow{2}{*}{$\begin{array}{l}\text { dTGR-S18886 } \\
(\mathrm{n}=12)\end{array}$} & \multicolumn{2}{|c|}{ ANOVA/K-W } \\
\hline & & & & $\mathrm{F}$ & $\mathrm{p}$ \\
\hline Initial body weight, $g$ & $118 \pm 10$ & $107 \pm 11$ & $110 \pm 17$ & 1.34 & 0.275 \\
\hline Body weight at sacrifice, $g$ & $245 ; 242 \pm 14$ & $200 ; 211 \pm 27^{\mathrm{b}}$ & $220 ; 212 \pm 17^{\mathrm{b}}$ & 10.35 & 0.006 \\
\hline Weight gain, $g$ & $125 ; 124 \pm 8$ & $100 ; 104 \pm 4$ & $103 ; 102 \pm 5$ & 16.60 & 0.0002 \\
\hline $\mathrm{SBP}, \mathrm{mm} \mathrm{Hg}$ & $98 ; 99 \pm 7$ & $163 ; 162 \pm 15^{\mathrm{b}}$ & $150 ; 149 \pm 13^{\mathrm{b}}$ & 23.56 & $7.7 \times 10^{-6}$ \\
\hline Heart weight, $g$ & $0.92 \pm 0.01$ & $1.21 \pm 0.11^{\mathrm{b}}$ & $1.16 \pm 0.13^{\mathrm{b}}$ & 19.77 & $2.3 \times 10^{-6}$ \\
\hline Heart/body weight, mg/g & $3.8 ; 3.8 \pm 0.3$ & $5.8 ; 5.8 \pm 0.6^{\mathrm{b}}$ & $5.4 ; 5.5 \pm 0.4^{\mathrm{b}}$ & 22.02 & $1.7 \times 10^{-5}$ \\
\hline Kidney/body weight, mg/g & $4.5 \pm 0.3$ & $4.6 \pm 0.3$ & $4.8 \pm 0.4$ & 2.16 & 0.131 \\
\hline Glomerular volume, $\mu^{3}$ & $495 \pm 79$ & $510 \pm 64$ & $487 \pm 61$ & 0.430 & 0.661 \\
\hline Glomerular cell number & $926 \pm 120$ & $1,071 \pm 88^{b}$ & $1,026 \pm 86$ & 6.12 & 0.006 \\
\hline Podocyte number & $278 \pm 45$ & $257 \pm 32$ & $268 \pm 59$ & 0.509 & 0.607 \\
\hline Mesangial cell number & $276 \pm 60$ & $351 \pm 51^{\mathrm{a}}$ & $310 \pm 38$ & 5.25 & 0.012 \\
\hline Endothelial cell number & $240 \pm 47$ & $346 \pm 39^{b}$ & $310 \pm 46^{\mathrm{b}}$ & 14.10 & $6.4 \times 10^{-5}$ \\
\hline Parietal cell number & $132 \pm 21$ & $137 \pm 15$ & $139 \pm 14$ & 0.434 & 0.652 \\
\hline Capillary length density, $\mathrm{mm} / \mathrm{mm}^{3}$ & $9,729 \pm 434$ & $11,345 \pm 640^{\mathrm{b}}$ & $11,218 \pm 1,243^{b}$ & 10.82 & 0.0004 \\
\hline Capillary cross-sectional area, $\mu \mathrm{m}^{2}$ & $36 ; 36 \pm 4$ & $26 ; 25 \pm 2^{\mathrm{b}}$ & $28 ; 28 \pm 2^{\mathrm{b}, \mathrm{c}}$ & 20.05 & $2.8 \times 10^{-5}$ \\
\hline
\end{tabular}

Results are means $\pm \mathrm{SD}$, or medians with means $\pm \mathrm{SD}$ for not normally distributed data.

$\mathrm{SD}=$ Sprague-Dawley rats; $\mathrm{dTGR}=$ double transgenic rats; Plac = placebo; $\mathrm{ANOVA}=$ one-way analysis of variance; $\mathrm{K}-\mathrm{W}=$ Kruskal-Wallis test; SBP = systolic blood pressure.

${ }^{\mathrm{a}} \mathrm{p}<0.05$ vs. SD; ${ }^{\mathrm{p}} \mathrm{p}<0.01$ vs. SD; ${ }^{\mathrm{c}} \mathrm{p}<0.05$ vs. dTGR-Plac.

In the dTGR-Plac, plasma cholesterol levels were higher. Triacylglycerol (TAG) concentration did not differ significantly. Plasma MDA levels were elevated. GPX activity increased. SOD activity remained unaffected (table 2). Body weight (comparable at the initiation of the experiment) was significantly lower in dTGR at sacrifice.

\section{Effects of S18886 in the dTGR (table 1)}

Compared to dTGR-Plac, S18886 decreased SBP by 13 $\mathrm{mm} \mathrm{Hg}$, but significance was not reached $(\mathrm{p}=0.55)$. Body weight, heart or kidney to body weight ratio remained unaffected. Plasma creatinine was not influenced. Creatinine clearance decreased. Proteinuria and polyuria were reduced, urine osmolarity increased (to nearly normal levels).

S18886 significantly improved renal morphology: glomerulosclerosis and tubulointerstitial fibrosis scores were lower (fig. 1, 2c, i). The vascular damage remained uninfluenced. Mesangiolysis, albeit not elevated in the dTGR-Plac, was suppressed (fig. 1, 2f). S18886 had no effect on mean glomerular volume (table 1), glomerular cell numbers (apart from slight decrease in mesangial and endothelial hypercellularity (table 1; fig. 2l), and the capillary length density. Mean capillary cross-sectional area

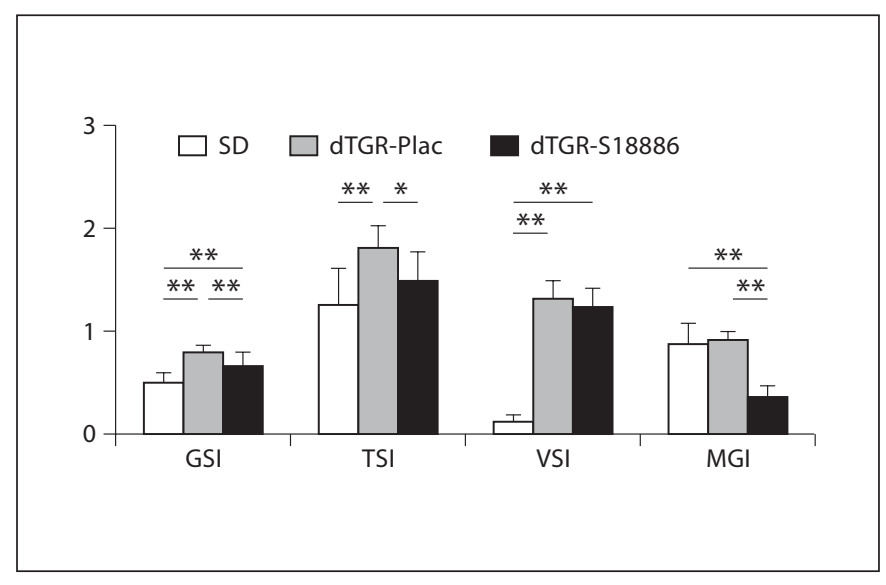

Fig. 1. Semiquantitative indices of renal damage. $\mathrm{SD}=$ SpragueDawley control rats; $\mathrm{dTGR}=$ double transgenic rats; Plac $=$ placebo; GSI = index of glomerulosclerosis; TSI = index of tubulointerstitial damage; VSI = index of vascular damage; $\mathrm{MGI}=$ mesangiolysis index; ${ }^{*} \mathrm{p}<0.05 ;{ }^{*} \mathrm{p}<0.01$.

was partially restored (table 1). S18886 reduced plasma cholesterol, but not TAG concentration. Plasma MDA concentration, GPX and SOD activities were not influenced (table 2). 

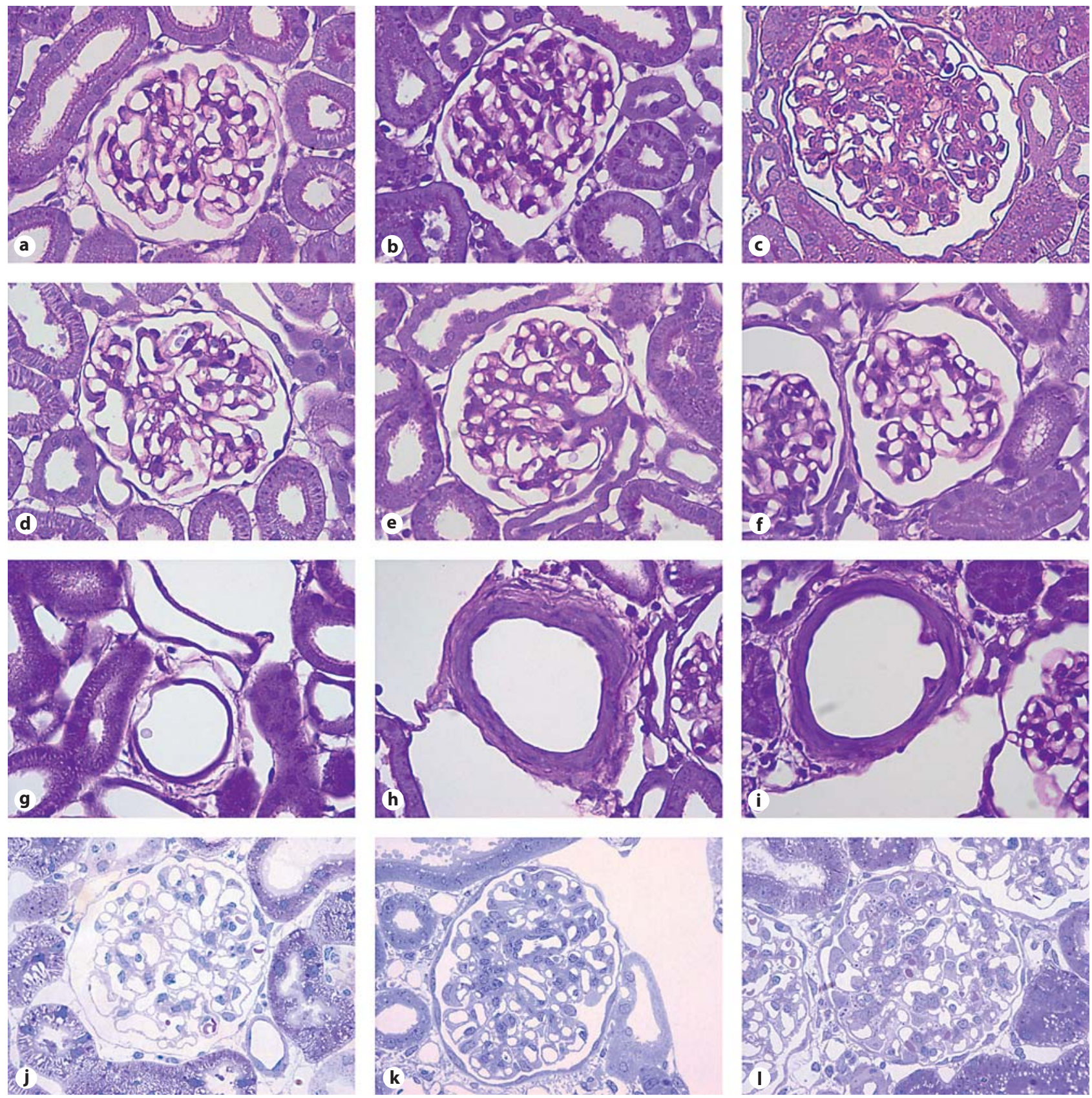

Fig. 2. Representative changes in renal morphology (GSI, MSI, vascular damage) in SD controls (first column), placebo-treated dTGR (second column) and S18886-treated dTGR (third column). a-c Mesangial matrix expansion and sclerosis were higher in dTGR-Plac (b) than in SD (a) and in dTGR-S188886 (c). Paraffin section, PAS stain, orig. magnif. $\times 20$. $\mathbf{d}-\mathbf{f}$ The index of mesangiolysis, i.e. dissolution of the mesangium with capillary widening, was comparable in controls (d) and dTGR-Plac (e); it was significantly lower in dTGR-S18886 (f). Paraffin section, PAS stain, orig. magnif. $\times 20 . \mathbf{g}-\mathbf{i}$ Vascular damage, i.e. thickening of the vascular wall, was significantly higher in dTGR-Plac (h) and dTGR-S18886 (i) than in SD (g). Paraffin section, PAS stain, orig. magnif. $\times 20$. j-I Representative semithin sections demonstrating glomerular hypercellularity in dTGR-Plac (k) and dTGR-S18886 (I) compared to SD (j). Semithin section, methylene blue and basic fuchsin stain, orig. magnif. $\times 20$. 
Table 2. Blood and urine chemistry

\begin{tabular}{|c|c|c|c|c|c|}
\hline & \multirow{2}{*}{$\begin{array}{l}\text { SD } \\
(n=10)\end{array}$} & \multirow{2}{*}{$\begin{array}{l}\text { dTGR-Plac } \\
(\mathrm{n}=14)\end{array}$} & \multirow{2}{*}{$\begin{array}{l}\text { dTGR-S18886 } \\
(\mathrm{n}=12)\end{array}$} & \multicolumn{2}{|c|}{ ANOVA/K-W } \\
\hline & & & & $\mathrm{F}$ & $\mathrm{p}$ \\
\hline Plasma creatinine, $\mu \mathrm{mol} / \mathrm{l}$ & $23 ; 25 \pm 6$ & $24 ; 23 \pm 3$ & $26 ; 27 \pm 5$ & 3.39 & 0.180 \\
\hline Creatinine clearance, $\mathrm{ml} / \mathrm{min}$ & $0.90 \pm 0.28$ & $0.85 \pm 0.18$ & $0.58 \pm 0.12^{\mathrm{a}, \mathrm{c}}$ & 5.62 & 0.010 \\
\hline Diuresis, $\mathrm{ml} / 24 \mathrm{~h}$ & $9 ; 10 \pm 3$ & $22 ; 22 \pm 8^{b}$ & $7 ; 7 \pm 4^{\mathrm{d}}$ & 24.03 & $6.0 \times 10^{-6}$ \\
\hline Proteinuria, $\mathrm{mg} / \mu \mathrm{mol}$ creatinine & $74 ; 81 \pm 34$ & $532 ; 558 \pm 218^{\mathrm{b}}$ & $133 ; 136 \pm 71^{\mathrm{d}}$ & 25.82 & $2.5 \times 10^{-6}$ \\
\hline Urine osmolarity, mosm $/ \mathrm{kg} \mathrm{H}_{2} \mathrm{O}$ & 1,$249 ; 1,386 \pm 527$ & $533 ; 556 \pm 211^{\mathrm{b}}$ & $992 ; 1,091 \pm 531^{\mathrm{c}}$ & 16.89 & 0.0002 \\
\hline Cholesterol, $\mathrm{mmol} / \mathrm{l}$ & $1.47 \pm 0.18$ & $1.84 \pm 0.12^{\mathrm{b}}$ & $1.69 \pm 0.17^{\mathrm{a}, \mathrm{c}}$ & 15.70 & $1.95 \times 10^{-5}$ \\
\hline TAG, mmol/l & $0.76 \pm 0.15$ & $0.83 \pm 0.19$ & $0.92 \pm 0.22$ & 1.94 & 0.161 \\
\hline $\mathrm{MDA}, \mu \mathrm{mol} / 1$ & $1.90 \pm 0.21$ & $2.40 \pm 0.30^{\mathrm{b}}$ & $2.38 \pm 0.49^{\mathrm{a}}$ & 6.30 & 0.006 \\
\hline SOD, U/g Hb & 2,$423 ; 2,554 \pm 415$ & 2,$387 ; 2,404 \pm 203$ & 2,$386 ; 2,326 \pm 417$ & 0.70 & 0.706 \\
\hline GPX, U/g Hb & $700 \pm 112$ & $917 \pm 71^{\mathrm{b}}$ & $828 \pm 152$ & 10.15 & 0.0004 \\
\hline
\end{tabular}

Results are means $\pm \mathrm{SD}$, or medians with means \pm SD for not normally distributed data.

$\mathrm{SD}=$ Sprague-Dawley rats; $\mathrm{dTGR}=$ double transgenic rats; Plac = placebo; $\mathrm{ANOVA}=$ one-way analysis of variance; $\mathrm{K}-\mathrm{W}=$ Kruskal-Wallis test; TAG = triacylglycerols; $\mathrm{MDA}=$ malondialdehyde; $\mathrm{SOD}=$ superoxide dismutase activity; GPX = glutathione peroxidase activity.

${ }^{a} \mathrm{p}<0.05$ vs. SD; ${ }^{\mathrm{b}} \mathrm{p}<0.01$ vs. SD; ${ }^{\mathrm{c}} \mathrm{p}<0.05$ vs. dTGR-Plac; ${ }^{\mathrm{d}} \mathrm{p}<0.01$ vs. dTGR-Plac.

\section{Discussion}

Protection from Ang-II-induced alterations in dTGR has been demonstrated by administration of Ang-II type 1 receptor blockers (ARB) [22], endothelin antagonists [23] and compounds with antioxidant/anti-inflammatory properties $[24,25]$. Our study presents first evidence that treatment with the TPr antagonist, S18886, results in a striking improvement of functional and morphological parameters in the Ang-II-induced nephropathy.

Although S18886 did not influence the systolic blood pressure significantly, reduction by $13 \mathrm{~mm} \mathrm{Hg}$ in mean $(-8 \%)$ might not be excluded as a renoprotective mechanism. The profound decline in proteinuria $(-76 \%)$ is impressive with regard to the persistent hypertension. Decline in elevated cholesterol levels probably reflects the forestalled proteinuria, and might not be attributed to a direct S18886 action. A comparable decrease in albuminuria, without blood pressure-lowering effect, was observed in diabetic apoE ${ }^{-/-}$mice administered S18886 [14]. Thromboxane, via its receptors, has been implicated in mediating glomerular permeability to albumin [26].

Despite the glomerulosclerosis and tubulointerstitial fibrosis, the creatinine clearance of the dTGR-Plac remained unaffected. This is most likely a sign of hyperfiltration possibly caused by increased plasma thromboxane with subsequent constriction of the vas efferens. Inhibition of TPr significantly reduced creatinine clearance, which might be explained by lower tonus of the vas efferens, followed by a functional decline of creatinine clearance. Thromboxane/thromboxane mimetics exerted contrasting renovascular effects in different experimental models: a predominant vasoconstriction of the vas afferens [27], the vas efferens [28], or of both arterioles [29]. However, the effects of endogenous thromboxane may differ from those of exogenously administered thromboxane agonists. The decrease of creatinine clearance resembles the well-known effects of angiotensinconverting enzyme inhibitors and ARBs, which are particularly pronounced in the presence of an activated renin-angiotensin system. Since we did not determine renal plasma flow, an explanation for the altered intrarenal hemodynamics is precluded.

Polyuria and a lower urinary osmolarity in the dTGRPlac were forestalled under S18886. Whether inhibition of TPr in the brainstem influenced the Ang-II-induced thirst [6] cannot be excluded, since the rats had free access to drinking water.

Amelioration of renal morphology in dTGR after inhibition of TPr was similar to that in diabetic apoE $\mathrm{E}^{-/-}$ mice. In these animals, S18886 reduced matrix deposition in the glomeruli and renal interstitium and the degenerative changes in tubules, in part via attenuation of various parameters of oxidative stress and inflammation [14]. Renal injury in the dTGR model was improved by administration of compounds with antioxidant/anti-in- 
flammatory properties $[24,25]$. S18886 did not significantly affect the altered parameters of oxidative status in dTGR-Plac. This might be due to limited effects of S18886 on hypertension, a prominent pro-oxidant condition. Persistent hypertension might also explain the insignificant attenuation of renal vasculopathy. Interestingly, S18886 profoundly reduced mesangiolysis, albeit the values in dTGR-Plac were within the normal range. In obese Zucker rats, a model with pathologically increased mesangiolytic score, S18886 significantly ameliorated mesangial damage, independent of blood pressure [15]. $\mathrm{TXA}_{2}$ delayed the clearance of macromolecules in the rat glomeruli and mesangial cells, while a TPr antagonist normalized these effects [30]. TXA ${ }_{2}$ also stimulated the production of plasminogen activator inhibitor-1 and plasminogen activators by mesangial cells through a TPrdependent mechanism [31]. Thus, the mesangium may represent an important target for S18886.

In apoE $\mathrm{E}^{-/-}$mice or the obese Zucker rats, S18886 does not lower blood pressure significantly $[14,15]$. Thus, in dTGR its effects on blood pressure need to be analyzed further, perhaps using telemetry. We assume that the insignificant blood pressure reduction in S18886-treated dTGR might not be the single mechanism for the marked improvement of renal damage. In rats, malignant hyper- tension retards weight gain. Both dTGR groups gained comparably less weight during the study than the control SD group. Persisting cardiac hypertrophy may be a consequence of the continued hypertension. Moreover, the striking antimesangiolytic effects of S18886 might not solely be attributed to the blood pressure decline.

We present here the first data that the administration of the TP receptor antagonist, S18886, markedly improves the renal damage in the model of transgenic rats harboring human renin and angiotensinogen genes. These findings suggest the fundamental role of activated TP receptors in the pathogenesis of Ang-II-induced renal injury, one of the major contributors to renal morbidity.

\section{Acknowledgements}

The authors would like to thank Dr. S. Corda and Dr. L. Lerond, Servier, Paris, for their support in drafting the manuscript. The technical assistance of Monika Klewer and Miriam Ramming is gratefully acknowledged. The study was supported in part by the Institut de Recherches Internationales Servier, Courbevoie, France, by the Deutsche Forschungsgemeinschaft (DFG, SFB423, Project B8) and by the Verein zur Bekämpfung der Hochdruckund Nierenkrankheiten Würzburg e.V., Germany.

\section{References}

1 Haas J-A, Krier J-D, Bolterman R-J, et al: Low-dose angiotensin II increases free isoprostane levels in plasma. Hypertension 1999;34:983-986.

2 Cohuet G, Struijker-Boudier H: Mechanisms of target organ damage caused by hypertension: therapeutic potential. Pharmacol Ther 2006;111:81-98.

3 Cracowski J-L, Devillier P, Durand T, et al: Vascular biology of the isoprostanes. J Vasc Res 2001;38:93-103.

4 Yamaguchi Y, Fenoy F-J, Roman R-J, Nasjletti A: Angiotensin II influences the renal hemodynamic response to blockade of thromboxane $\mathrm{A}_{2}$ and prostaglandins $\mathrm{H}_{2}$ receptors. J Pharmacol Exp Ther 1992;263:905-909.

5 Brown G-P, Venuto R: Thromboxane receptors in human kidney tissues. Prostaglandins Other Lipid Mediat 1999;57:179-188.

6 Kitiyakara C, Welch W-J, Verbalis J-G, Wilcox C-S: Role of thromboxane receptors in the dipsogenic response to central angiotensin II. Am J Physiol 2002;282:R865-R869.

7 Simonet S, Descombes J-J, Vallez M-O, et al: S18886, a new thromboxane (TP)-receptor antagonist is the active isomer of S18204 in all species, except in the guinea-pig. Adv Exp Med Biol 1997;433:173-176.
8 Alexander SP, Mathie A, Peters JA: Guide to receptors and channels (GRAC). Br J Pharmacol 2007;150(suppl 1):S1-S168.

9 Verbeuren T-J: Terutroban and endothelial TP receptors in atherogenesis. Med Sci (Paris) $2006 ; 22: 437-443$.

10 Viles-Gonzalez J, Fuster V, Corti R, et al: Atherosclerosis regression and TP receptor inhibition: effect of S18886 on plaque size and composition - a magnetic resonance imaging study. Eur Heart J 2005;26:1557-1561.

11 Worth N, Berry C, Thomas A, Campbell J-H: S18886, a selective TP receptor antagonist. inhibits development of atherosclerosis in rabbits. Atherosclerosis 2005; 183:65-73.

12 Cayatte A-J, Du Y, Oliver-Krasinski J, et al: The thromboxane receptor antagonist S18886 but not aspirin inhibits atherogenesis in apoE-deficient mice: evidence that eicosanoids other than thromboxane contribute to atherosclerosis. Arterioscler Thromb Vasc Biol 2000;20:1724-1728.

13 Zuccollo A, Shi C, Mastroianni R, et al: The thromboxane $\mathrm{A}_{2}$ receptor antagonist, S18886, prevents enhanced atherogenesis caused by diabetes mellitus. Circulation 2005;112:3001-3008.
$14 \mathrm{Xu} \mathrm{S}$, Jiang B, Maitland K-A, et al: The thromboxane receptor antagonist S18886 attenuates renal oxidant stress and proteinuria in diabetic apolipoprotein E-deficient mice. Diabetes 2006;55:110-119.

15 Šebeková K, Eifert T, Klassen A, et al: Renal effects of S18886 (terutroban), a TP receptor antagonist, in an experimental model of type 2 diabetes. Diabetes 2007;56:968-974.

16 Luft F-C, Mervaala E, Muller D, et al: Hypertension-induced end organ damage: a new transgenic approach to an old problem. Hypertension 1999;33:389-395.

17 Fiebeler A, Schmitz F, Muller D-N, et al: Mineralocorticoid receptor affects AP-1 and nuclear factor- $\kappa \mathrm{B}$ activation in angiotensin II-induced cardiac injury. Hypertension 2001;37:787-793.

18 Schwarz U, Amann K, Orth S-R, et al: Effect of $1,25(\mathrm{OH})_{2}$ vitamin $\mathrm{D}_{3}$ on glomerulosclerosis in subtotally nephrectomized rats. Kidney Int 1998;53:1696-1705.

19 Wong S-H, Knight J-A, Hopfer S-M, et al: Lipoperoxides in plasma as measured by liquid-chromatographic separation of malondialdehyde-thiobarbituric acid adduct. Clin Chem 1987;33:214-220. 
20 Gross M-L, Ritz E, Schoof A, et al: Renal damage in the SHR/N-cp type 2 diabetes model: comparison of an angiotensin-converting enzyme inhibitor and endothelin receptor blocker. Lab Invest 2003;83:12671277.

21 Weibel ER: Measuring through the microscope: development and evolution of stereological methods. J Microsc 1989;155:393403.

22 Mervaala E, Dehmel B, Gross V, et al: Angiotensin-converting enzyme inhibition and AT1 receptor blockade modify the pressurenatriuresis relationship by additive mechanisms in rats with human renin and angiotensinogen genes. J Am Soc Nephrol 1999;10: 1669-1680.
23 Muller D-N, Mervaala E-M, Schmidt F, et al: Effect of bosentan on NF- $\kappa \mathrm{B}$, inflammation, and tissue factor in angiotensin II-induced end-organ damage. Hypertension 2000;36: 282-290.

24 Mervaala E, Finckenberg P, Lapatto R, et al: Lipoic acid supplementation prevents angiotensin II-induced renal injury. Kidney Int 2003;64:501-508.

25 Helkamaa T, Finckenberg P, Louhelainen M, et al: Entacapone protects from angiotensin II-induced inflammation and renal injury. J Hypertens 2003;21:2353-2363.

26 Remuzzi G, Fitzgerald G-A, Patrono C Thromboxane synthesis and action within the kidney. Kidney Int 1992;41:1483-1493.

27 Hayashi K, Loutzenhiser R, Epstein M: Direct evidence that thromboxane mimetic U44069 preferentially constricts the afferent arteriole. J Am Soc Nephrol 1997;8:25-31.
28 Wilkes B-M, Solomon J, Maita M, Mento PF: Characterization of glomerular thromboxane receptor sites in the rat. Am J Physiol. 1989;256:F1111-F1116.

29 Baylis C: Effects of administered thromboxanes on the intact, normal rat kidney. Ren Physiol 1987;10:110-121.

30 Nagao T, Koseki J, Suzuki Y, Nagamatsu T. Thromboxane $\mathrm{A}_{2}$ causes retarded clearance of aggregated protein in glomeruli of nephritic mice. Eur J Pharmacol 2001;413:271279.

31 Coffman TM, Spurney RF, Mannon RB, Levenson R: Thromboxane $\mathrm{A}_{2}$ modulates the fibrinolytic system in glomerular mesangial cells. Am J Physiol 1998;275:F262F269. 